\title{
OCORRÊNCIA DE HEPATITES NÃO-ANÃO-B EM UNIDADE DE HEMODIÁLISE
}

\author{
Clarina Takahashi1, Clara F. T. Yoshida2, Ana Maria C. Gaspar2, Marcla L. Baptista2, \\ Marcos Hoette ${ }^{1}$ e Frederico Ruzany 1
}

\begin{abstract}
A monitorização mensal de alanina aminotransferase ( $A L T$ ) sérica de pacientes em hemodiálise e os testes sorológicos para exclusões de infecções por vírus da hepatite $A$ ( $H A V)$, virus da hepatite $B$ (HBV), citomegalovirus (CMV) e virus Epstein-Barr (EBV), permitiu-nos identificar 11 casos de hepatites não-A, não-B em 111 indivíduos avaliados durante o periodo de 12 meses e acompanhados por 2 anos.

Foram observados 3 padrões de atividade de ALT: elevação em pico monofásico em 2, bifásico ou polifásico em 6 e em platô em 3 pacientes. Individiduos com padrão monofásico exibiram os niveis mais elevados de ALT.

Cinco pacientes apresentaram normalização bioquímica persistente 4,8 meses em média após o início da elevação aguda e seis evoluiram com ascensão crônica de $A L T$ durante o periodo de estudo. $A$ hepatite não- $A$, não-B foi, predominantemente, assintomática e anictérica, sempre antecedida por transfusões sangüineas e com maior incidência nos seis primeiros meses de terapia dialítica dos pacientes.
\end{abstract}

Palavras-chaves: Hepatite não-A, não-B. Hemodiálise. Transfusão sagüinea.

Depois que a adoção de medidas para o controle da infecção pelo vírus da hepatite B (HBV) em unidade de hemodiálise (HD) surtiram efeito, novas formas de hepatites, provavelmente não- $A$, não-B (HNANB) tornaram-se notáveis entre os pacientes e funcionários desses locais.

Evidencias clinicas ${ }^{1920}$ e experimentais 13222630 sugerem que mais de um agente seja responsável por essa entidade.

$\mathrm{Na}$ ausência de testes específicos para o diagnóstico das HNANB, são utilizados marcadores indiretos e a dosagem da enzima alanina aminotransferase (ALT) faz parte de tais marcadores.

Uma variedade de agentes, contudo, está implicada na elevação de ALT em pacientes com doenças renais em estágio terminal. Ensaios sorológicos permitem-nos a identificação de pacientes com hepatites A, B, virus Epstein-Barr (EBV) e citomegalovirus (CMV) nesse grupo de pacientes. Outras viroses humanas (Coxsackie B e Herpes simples), medicamentos (aspirina, acetaminofen e metildopa), álcool, injúria anóxica por insuficiência cardíaca congestiva e doenças biliares fazem parte do diagnóstico diferencial em pacientes urêmicos que se apresentam com provas de função hepática anormais 6 .

1. Clínica de Doenças Renais - Rio de Janeiro.

2. Departamento de Virologia - Fundação Oswaldo Cruz Avenida Brasil, 4365 CEP 21040 - Rio de Janeiro.

Recebido para publicação em 5/5/88
Este trabalho tem como intento descrever nossa experiência com as HNANB, em uma população de pacientes submetidos à HD crônica destacando-se as caracteristicas dessas doenças e sua relação com transfusões sangüíneas.

\section{MATERIAIS E MÉTODOS}

\section{Descrição da Unidade de Diálise}

O trabalho foi desenvolvido em uma unidade de HD satélite, equipada com sistema de tratamento de água por osmose reversa e desionização.

Os pacientes são individualizados em suąs próprias máquinas do tipo "tanque" e de proporção, cujos dialisadores são da modalidade de fibras capilares, adotando-se a prática de reutilização em uma central própria.

Nos intervalos do tratamento, processa-se a desinfecção das máquinas com hipoclorito de sódio a $0,5 \%$.

A unidade possui isolamento para pacientes infectados pelo HBV cuja prevalência era de $10 \%$ na ocasião do estudo.

Todos os outros materiais utilizados nessa unidade são descartáveis e os funcionários exercem suas atividades com luvas.

\section{Caracterização do grupo em estudo}

Foram acompanhados 111 pacientes portadores de doença renal, em estágio terminal, de variadas etiologias, com idades de 7 meses a 82 anos (mé- 
dia $=44,6 \pm 16,6$ ), sendo $62 \%$ do sexo masculino e $38 \%$ do sexo feminino, que permaneceram em tratamento através de hemodiálise por um periodo mínimo de 3 meses.

\section{Obtenção das amostras}

Doze amostras sangüineas, com intervalos mensais, foram coletadas de cada paciente e submetidas à determinação da atividade de ALT.

Caso o valor dessa enzima fosse 4 vezes ou mais elevado em relação ao valor normal para urêmicos, nova amostra era obtida com intervalo de 5 dias para a realização do mesmo exame. Esse valor sendo confirmado, procedia-se a avaliação clinica e os esforços eram dirigidos para a exclusão de outros fatores causais de lesão hepatocelular, como: ingestão alcoolica abusiva, drogas hepatotóxicas, doenças de trato biliar, insuficiência cardíaca direita, carcinoma metastático e infecção por HAV, HBV, CMV e EBV.

\section{Métodos laboratoriais}

\section{A - Teste bioquímico}

A dosagem da enzima alanina aminotransferase foi realizada a $30^{\circ} \mathrm{C}$, por um método cinético otimizado, e expressa em Unidades internacionais/mililitro (UI/ml), com valores normais para urêmicos em hemodiálise até $28 \mathrm{UI} / \mathrm{ml}$.

\section{B - Testes sorológicos}

1 - Testes para diagnóstico de hepatite $B$ :

- Determinação de HBsAg pela técnica de radioimunoensaio (Ausria II-125, Abbott Lab.) - Determinação de anti-HBc pelo teste de radioimunoensaio (Corab, Abbott Lab.) - Determinação de $\mathrm{HBeAg} /$ anti-HBe pela técnica de imunodifusão descrita por Magnius e Espmark, 1972, modificada ${ }^{18}$ Determinação de anti-HBs pela técnica de radioimunoensaio (Ausab, Abbott Lab).

\section{2 - Testes para diagnóstico de hepatite A:}

- Determinação de anticorpos IgM e IgG para hepatite A pela técnica de radioimunoensaio (Abbott Lab.)

3 - Testes para diagnóstico de CMV:

- Reação de fixação de complemento, soros pareados com intervalos de 4 semanas. - Determinação de IgM e IgG anti-CMV por imunofluorescência.
4 - Testes para diagnóstico de EBV:

- Determinação de anticorpos heterófilos Reação de Paul-Bunnell.

Os pacientes considerados como portadores de HNANB foram avaliados, quanto à duração da diálise, antes do início da elevação enzimática, presença e número de transfusões sangüineas administradas, num período prévio de 6 meses antes do mesmo evento, niveis absolutos de ALT, durante 24 meses, apresentação clínica e prognóstico dessa doença.

\section{RESULTADOS}

Durante o periodo de estudo, as HNANB ocorreram em 11 dos 111 pacientes hemodialisados, na Clínica de Doenças Renais - RJ, sendo 6 do sexo feminino e 5 do sexo masculino, na faixa etária de 9 a 63 anos com mediana de 41 anos.

O periodo de exposição à diálise, antes do início da hepatite, variou de 1 a 29 meses, sendo que $72,7 \%$ eram pacientes com tempo menor ou igual a 6 meses em tal tratamento.

A exclusão das infecçōes, pelo $\mathrm{HAV}, \mathrm{HBV}$, CMV e EBV nos 11 pacientes com HNANB, foi verificada ao longo do período de estudo. Marcadores especificos de infecção de cada etiologia foram pesquisados na fase inicial ou anterior a alteração dos niveis de ALT e pareados com amostras subsequentes, colhidas durante o periodo de acompanhamento. Não se encontrou nenhum anticorpo do tipo IgM contra hepatite $\mathrm{A}$, porém, anticorpos do tipo IgG foram observados em 10 pacientes, caracterizando seu estado imune, restando apenas 1 paciente susceptivel à hepatite $\mathrm{A}$. Com relação à hepatite $\mathrm{B}, 4$ pacientes apresentavam imunidade, com presença de anticorpos anti-HBs e ou anti-HBc, enquanto que 7 pacientes não apresentaram nenhum marcador sorológico de HBV. Anticorpos, contra EBV e CMV, foram detectados e titulados em amostras seriadas e mantiveram-se inalterados, demonstrando ausência de ambas as infecçōes durante o periodo de alteração das ALT.

As hepatites foram consideradas agudas em 5 pacientes; nos 6 outros houve persistência de níveis elevados de ALT ao longo do estudo ou até a perda do acompanhamento por óbito ou transplante renal.

Os valores anormais, o periodo e o padrão de alteração da ALT, nas formas agudas e crônicas, estão representados na tabela 1 . Três pacientes, um agudo $\mathrm{e}$ dois crônicos, apresentaram sinais e sintomas di doença, mas somente um paciente, que evoluiu para a forma crônica, manifestou icterícia.

No quadro bioquímico chamou atenção o padrão flutuante de aumentos, na enzima ALT, onde periodos de atividade enzimática elevada alternavam- 
Takahashi C, Yoshida CFT, Gaspar AMC, Baptista ML, Hoette M, Ruzany F. Ocorrência de hepatites não-A não-B em unidade de hemodiálise. Revista da Sociedade Brasileira de Medicina Tropical 21: 105-111, Jul-Set, 1988

se com períodos de atividade próximos à normalidade, durando semanas ou meses.

Três padrões de alteração, em relação à atividade de ALT, foram observados: 2 pacientes com padrão monofásico (Fig. 1); 6 com elevações bifásicas ou polifásicas (Fig. 2) e 3 com elevações em platô.

Em nosso estudo os pacientes, com elevações monofásicas, apresentaram niveis mais elevados de
ALT e exteriorização clínica de hepatite em um deles, com náuseas, vômitos, hepatomegalia dolorosa. Esses pacientes apresentaram recuperação clínica e bioquímica.

Um paciente, com padrão enzimático polifásico e evolução para a forma crônica, foi submetido à biopsia hepática, cujo estudo histológico evidenciou hepatite crônica persistente.

Tabela 1 - Características das hepatites não- $A$ não-B agudas e crônicas em relação à ALT na unidade de hemodiálise.

\begin{tabular}{lccl}
\hline Classificação & $\begin{array}{c}\text { Alteração de ALT } \\
\text { (média } \pm \text { desvio padrão) }\end{array}$ & $\begin{array}{c}\text { Período } \\
\text { (meses) }\end{array}$ & $\begin{array}{c}\text { Padrão de } \\
\text { alteração de ALT }\end{array}$ \\
\hline \multirow{4}{*}{ Aguda } & $650 \pm 494,9$ & 2 & Monofásico \\
& $172 \pm 190,1$ & 3 & Monofásico \\
& $69,8 \pm 50,9$ & 5 & Polifásico \\
& $178,7 \pm 131,2$ & 9 & Polifásico \\
& $464 \pm 323,3$ & 5 & Bifásico \\
\hline \multirow{4}{*}{ Crônica } & $104 \pm 49,6$ & $10^{*}$ & Platô \\
& $59,1 \pm 55,3$ & 24 & Platô \\
& $53 \pm 35,8$ & 20 & Platô \\
& $110 \pm 101,2$ & $11^{* * *}$ & Polifásico \\
& $88,5 \pm 119,6$ & $13^{* * *}$ & Polifásico \\
& $56,5 \pm 38.3$ & 24 & Polifásico \\
\hline
\end{tabular}

* Óbito

* - Saída para transplante

** - Óbito, com biópsia hepática

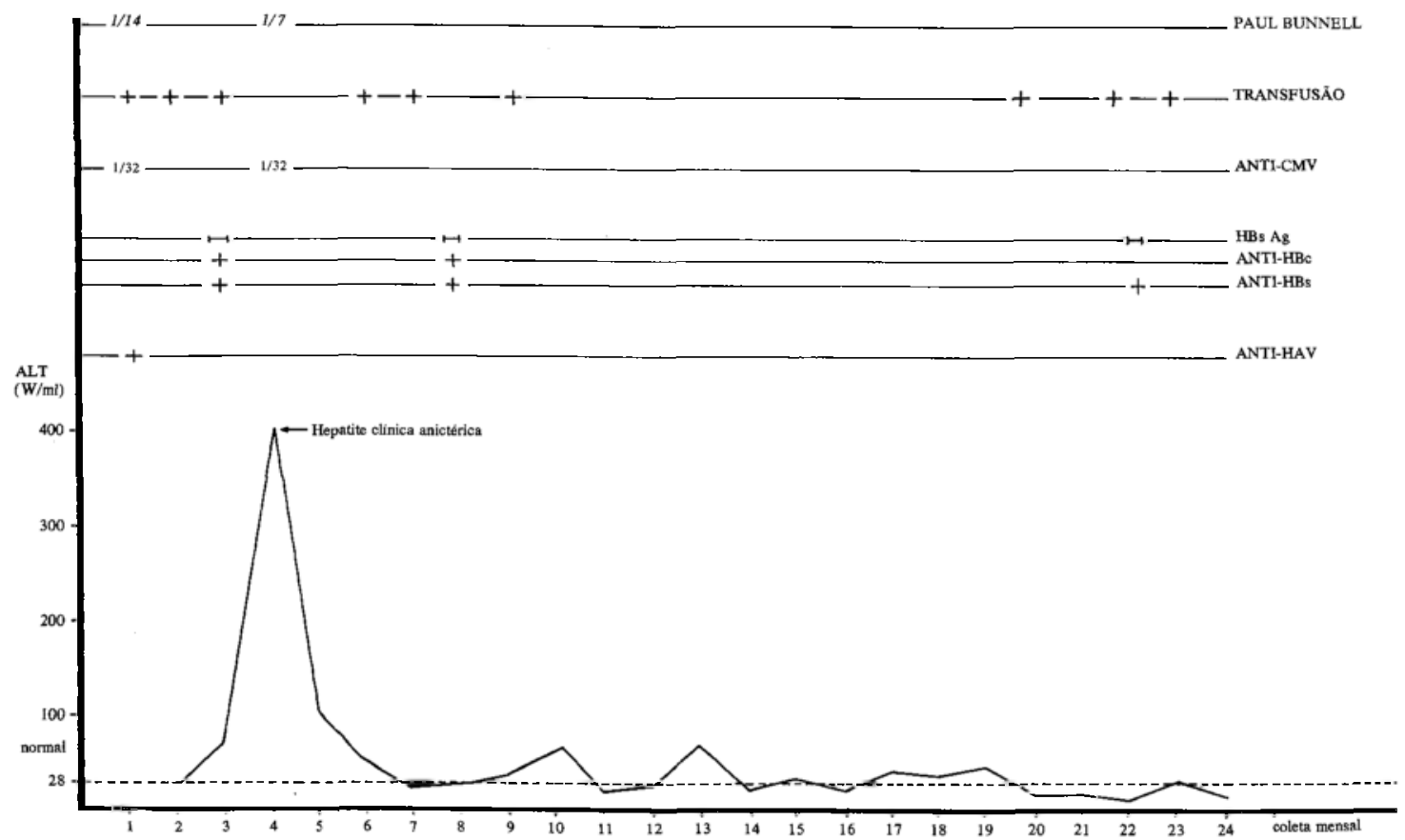

Fig. 1-Padrão de alteração de ALT, em pico monofásico, em pacientes com HNANB. 
Takahashi C, Yoshida CFT, Gaspar AMC, Baptista ML, Hoette M, Ruzany F. Ocorrência de hepatites não-A näo-B em unidade de hemodiálise. Revista da Sociedade Brasileira de Medicina Tropical 21: 105-111, Jul-Set, 1988

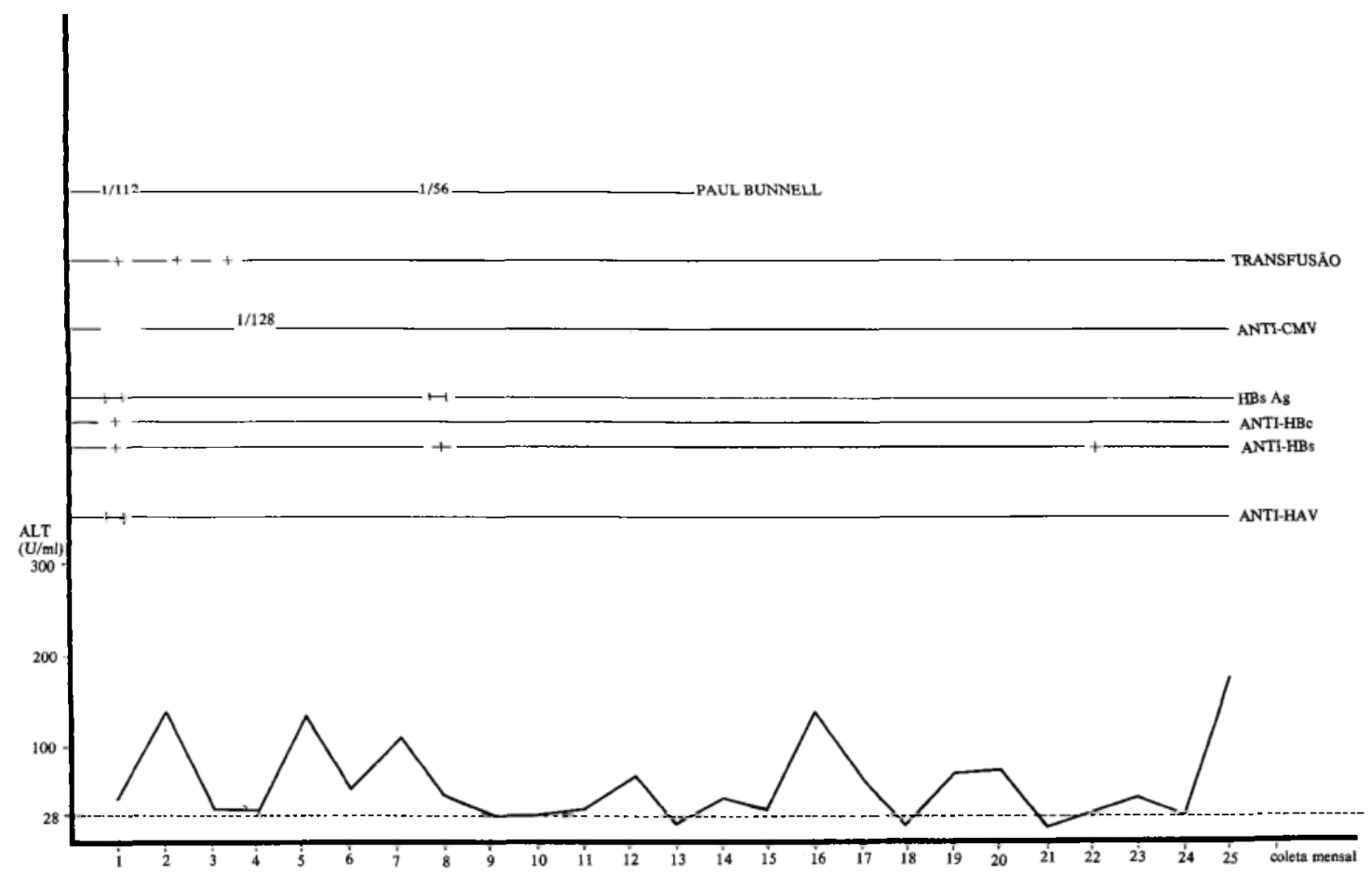

Fig. 2 - Padrão polifásico de alteração de ALT em pacientes com HNANB.

Todos os 11 pacientes tinham antecedentes de transfusões sangüíneas nos últimos 6 meses (Fig. 3). Dos restantes, 100 pacientes, 53\% também receberam uma ou mais transfusões de papas de hemácias durante o periodo de avaliação.

Observamos 32 pacientes, nos primeiros 6 meses de tratamento (iniciantes), dos quais 17 receberam uma ou mais transfusões e 8 desenvolveram hepatite não-A, não-B. Nesse grupo de iniciantes, nos 15 restantes que não se submeteram à hemotransfusão, essa entidade não foi detectada.

\section{DISCUSSÃO}

Estudos sobre hepatites pós-transfusionais ${ }^{10}$, bem como relatos clínicos epidemiológicos revelaram um terceiro tipo de hepatite viral, a hepatite não-A, não-B ${ }^{827}$.

Experimentos em chimpanzés forneceram evidências claras sobre a existência de um agente transmissível não-A, não-B com demonstração de estado de portador crônico assintomático ${ }^{324}$.

Em pacientes submetidos a tratamento pela HD crônica, comprovadamente de alto risco de aquisição de hepatites virais, esta particular forma, de hepatite não-A, não-B, também, apresenta-se com alta freqüência ${ }^{11}{ }^{29} . \mathrm{Na}$ análise de uma unidade de diálise, livre de infecção pelo HBV, composta de 111 pacien-

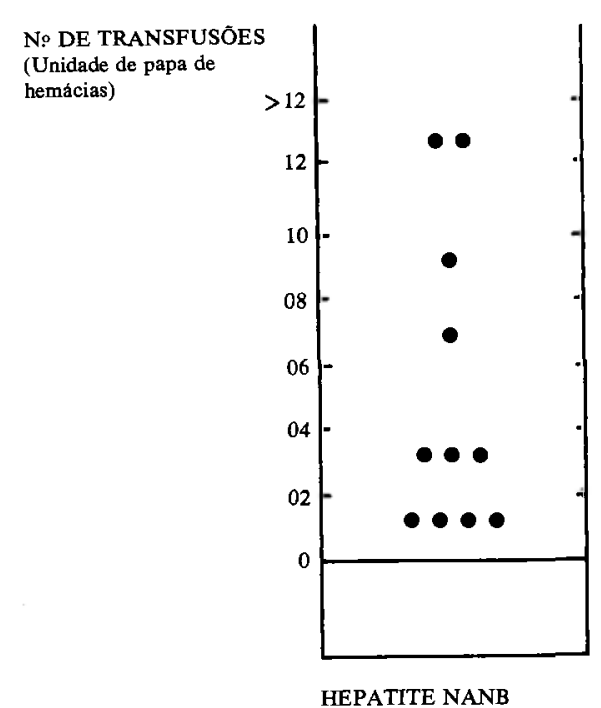

Fig. 3 - Número de transfusōes de sangue fornecido, aos pacientes portadores de HNANB, na unidade de hemodiálise. 
tes, observou-se uma incidência anual de HNANB de $4,6 \%{ }^{23}$. Num estudo multicêntrico americano, constituido de 2070 pacientes em HD, foram verificadas não só uma incidência anual de HNANB de 5,8\%, com cifras variando de 0 a $16 \%$ nos diversos centros participantes, como também a correlação entre HNANB e transfusões sangüineas recentes. A taxa de ataque anual, para os funcionários, foi de $0,8 \% \mathrm{com}$ variação de 0 a $2,3 \%$ e o fator de risco para esse grupo foi relacionado a acidente percutâneo prévio. A importância desse modo de transmissão e a ausência de casos secundários entre os membros da família, dos pacientes e dos funcionários afetados, proporcionaram evidências para transmissão predominantemente percutânea em unidade de diálise e a exigência dessa forma de exposição para a transmissão eficiente de HNANB ${ }^{9}$.

As HNANB compreendem ainda $25 \%$ das hepatites agudas e $70 \%$ das crônicas observadas em pacientes com transplantes renais ${ }^{28}$. Elas desenvolvem-se em $7 \%$ dos receptores de sangue e ocorrem em até $90 \%$ dos casos de hepatites pós-transfusionais ${ }^{12}$. Tem sido implicada em 9 a $20 \%$ dos casos de hepatites esporádicas $^{7}$ e em $53 \%$ dos casos de hepatites recidivantes em viciados em drogas ${ }^{19}$. O centro de diálise também funciona como um importante fator epidemiológico para explicar a ocorrência de HNANB nos pacientes não transfundidos ${ }^{21}$.

Em nosso acompanhamento 11 (10\%) pacientes em programa regular de hemodiálise apresentaram características de hepatite não-A, não-B e esses constituíram $17,1 \%$ de todos os receptores de sangue da unidade no periodo estudado.

A epidemiologia da hepatite não-A, não-B, em nossa unidade foi claramente relacionada à transfusão sangüinea uma vez que todos os pacientes foram transfundidos nos 6 meses precedentes ao inicio das hepatites e a maioria no primeiro semestre de tratamento dialítico. Além disso não se detectou nenhum caso nos pacientes, com o mesmo tempo em diálise, sem exposição à hemotransfusão, relegando ao centro de hemodiálise, em si, um papel epidemiológico menos importante na ocorrência desta doença.

Geralmente as hepatites não- $A$, não- $B$ póstransfusionais são assintomáticas e anictéricas, com evolução prolongada manifestada por elevações persistentes ou intermitentes de ALT ${ }^{13}$; estas observações também foram constatadas em nossa série.

Tateda e cols decreveram 3 padrões de elevaçōes de ALT em 116 pacientes com HNANB ${ }^{25}$. Um grupo $(47 \%)$ tinha aumento rápido monofásico em pico de $A L T$, seguido por uma queda rápida. Um segundo grupo (24\%) experimentou um aumento bifásico remanescente de padrão de enzima flutuante. Nos $29 \%$ restantes, a atividade de ALT aumentou e manteve-se persistente, em platô.
Observaçōes semelhantes de alterações enzimáticas do tipo monofásicas e bifásicas ou multifásicas foram descritas por Berg e cols. ${ }^{4}$ no acompanhamento das formas de HNANB agudas.

Em nosso estudo, foram observadas elevações monofásicas em $2(18,1 \%)$, bifásicas ou multifásicas em $6(54,4 \%)$ e em platô em $3(18,2 \%)$ pacientes. De forma semelhante a pacientes de outros estudos, que apresentaram niveis de ALT flutuante, as anormalidades bioquimicas persistiram por muitos meses.

$\mathrm{Na}$ ausência de marcadores especificos para a HNANB, enfatizamos a possibilidade das formas agudas com remissão bioquímica cursarem para o estado de portador crônico assintomático além da conferência de imunidade. Sendo assim, a incidência maior de HNANB, nos pacientes iniciantes em diálise, comparada com os mais antigos, todos com hemotransfusão prévia, poderia ser explicada pela maior prevalência do estado de portador crônico assintomático ou imunidade nos últimos. Ressaltamos ainda que, os pacientes antigos podem ter recebido hemoderivados em algum momento, desde o início de seus tratamentos, que antecedem o periodo de nosso estudo, tendo tido outras oportunidades para a aquisição de HNANB.

$\mathrm{Na}$ unidade de diálise em estudo, portanto, o mais importante fator epidemiológico foi a hemotransfusão, mas a aquisição de doença ocorreu mais freqüentemente durante as primeiras exposiçōes a esses derivados. Os pacientes em homodiálise recebem esses produtos geralmente no inicio de sua terapia dialítica, fase em que estão mais urêmicos, hipervolêmicos e anêmicos.

Em virtude do periodo de atividade enzimática normal, que pode durar vários meses entre os aumentos enzimáticos episódicos, torna-se dificil a determinação da convalescença verdadeira. Muito cuidado deve ser tomado para não confundir esses periodos, de exacerbação episódica de HNANB prolongada, com ocorrências de episódios múltiplos distintos, de hepatite aguda, separadas por longos intervalos de função hepática normal, histologicamente caracterizados como descrito em viciados por drogas ${ }^{14}$.

Koretz e cols ${ }^{16}$ reportaram que oito dos 18 pacientes, com HNANB pós-transfusional, tinham hepatite crônica ativa e dois pacientes dessa série tinham evidências de cirrose. Tais observações, da presença dẹ hepatite crônica em uma grande maioria e cirrose em menor escala, nos pacientes portadores de HNANB, foram também descritas por outros autores $^{5,15}$.

Em nosso grupo, apenas um paciente foi submetido à biópsia hepática; a histologia evidenciou hepatite crônica persistente.

Uma outra causa potencial, de inflamação e fibrose hepática, em pacientes crônicamente hemodialisados, é a disseminação e migração de silicone das 
Takahashi C, Yoshida CFT, Gaspar AMC, Baptista ML, Hoette M, Ruzany F. Ocorrência de hepatites não-A não-B em unidade de hemodiálise. Revista da Sociedade Brasileira de Medicina Tropical 21: 105-111, Jul-Set, 1988

linhas de diálises, através do segmento da bomba de sangue. Em pacientes em diálise, com disfunção hepática crônica, foram identificadas partículas de silicone, geralmente associadas a granulomas no figado e outros órgãos ${ }^{17}$. Entretanto, a probabilidade de que esse fenômeno seja responsável por uma proporção substancial de HNANB associada à diálise parece pequena. A associação estatística a transfusões sangüineas, os casos adquiridos ocupacionalmente, nos funcionários de HD e a ausênica de silicone e granulomas no material histológico de pacientes são argumentos a favor de um agente transmissível ${ }^{9} 12$.

Concluímos que, na unidade de diálise em estudo, as hepatites não-A, não-B foram observadas sempre precedidas por transfusōes sangüineas, incidindo predominantemente nos 6 primeiros meses de tratamento, apresentando elevações enzimáticas em padrão polifásico e um curso crônico assintomático na maioria dos casos.

\section{SUMMARY}

Through monthly monitorization of alanine amino transferase (ALT) in hemodialysis patients and serological tests for exclusion of HAV (hepatitis $A$ virus), HBV (hepatitis B virus), CMV (cytomegalovirus) and $E B V$ (Epstein-Barr virus) infections, it was possible to identify 11 cases of non- $A$, non- $B$ hepatitis among 111 individuals evaluated in a period of 12 months and followed-up for 2 years.

Three patterns of ALT activity were observed: an elevation in monophasic peak in 2 patients, biphasic and polyphasic in 6 patients and elevation in plateau in three others. Patients with the monophasic pattern showed the most elevated levels of $A L T$.

Five patients showed biochemical normalization within approximately 4.8 months after the beginning of acute elevation and 6 evolved with chronic intermittent elevation during the period of study.

Hepatitis non- $A$, non- $B$ was predominantly asymptomatic and anicteric, always preceeded by blood tranfusions and with higher incidence in the 6 first months after hemodialysis.

Key-words: Non-A Non-B hepatitis. Hemodialysis. Blood transfusion.

\section{AGRADECIMENTOS}

Agradecemos a valiosa colaboração das Dras. Rita Maria Ribeiro Nogueira e Roseane Seabra Nogueira pela realização da sorologia para diagnóstico de CMV e EBV respectivamente e a Luiz Antonio C. Mercadante pela assistência técnica e laboratorial prestada.

\section{REFERÊNCIAS BIBLIOGRÁFICAS}

1. Aach RD, Kahn RA. Post-transfusion hepatitis: current perspectives. Annals of Internal Medicine 92: 539-546, 1980.

2. Alter HJ, Purcell RH, Holland PV, Alling DW, Koziol DE. Donor transaminase and recipient hepatitis. Impact on blood transfusion services. Journal of the American Medical Association 246: 630-634, 1981.

3. Alter HJ, Purcell RH, Holland PV, Popper H. Transmissible agent in non-A, non-B hepatitis. Lancet 1:459463,1978 .

4. Berg PA, Stromp R, Ewers C, Schmeisser W, Dolle W, Flehmig B. Epidemiologie und klinik der Non-A, Non-B hepatitis. Eine retrospektive Studie aus den Jahren 1970-1976. Deutsche Medizinische Wochenschrift 105:751-755, 1980.

5. Berman M, Alter HJ, Ishak KG, Purcell RH, Jones EA. The chronic sequelae of non- $A$, non-B hepatitis. Annals of Internal Medicine 91:1-6, 1979.

6. Brenner EM, Rector FC. The kidney. vol. II, 2nd Ed, p. 2503, Philadelphia, WB Sauders, 1981.

7. Dienstag JL. Non-A, non-B hepatitis. Advances in Internal Medicine 26: 187-233, 1987.

8. Dienstag JL, Alaama A, Mosley JW, Redeker AG, Purcell RH. Etiology of sporadic hepatitis B surface antigen-negative hepatitis. Annals of Internal Medicine 87:1-6, 1977.

9. Dienstag JL, Stevens CE, Szmuness W. The epidemiology of non- $A$, non-B hepatitis: emerging patterns. In: (ed.) Gerety RJ. Non- $A$, non-B hepatitis. Academic Press, New York p. 119-138, 1981.

10. Feinstone SM, Kapikian AZ, Purcell RH, Alter HJ, Holland PV. Transfusion-associated hepatitis not due to viral hepatitis A or B. New England Journal of Medicine 292: 767-770, 1975.

11. Gaibraith RM, Dienstag JL, Purcell RH, Gower RH, Zuckerman AJ, Williams R. Non-A, non-B hepatitis associated with chronic liver disease in a haemodialysis unit. Lancet 1: 951-953, 1979.

12. Gubin N. Spallation of silicone from blood-pump tubing in hemodialysis. New England Journal of Medicine 307: 319, 1982.

13. Hollinger FB, Mosley JW, Szmuness W, Aach RD, Peters RL, Stevens C. Transfusion-transmitted viruses study: experimental evidence for two non- $A$, non-B, hepatitis agents. Journal of Infectious Diseases 142: 400-407, 1980.

14. Karvountzis GG, Mosley JW, Redeker AG. Serologic characterization of patients with two episodes of acute viral hepatitis. American Journal of Medicine 58:815$822,1975$.

15. Knodell RG, Conrad ME, Ishak KG. Development of chronic liver disease after acute non-A, non-B posttransfusion hepatitis: role of gamma-globulin prophylaxis in its prevention. Gastroenterology 72: 902-909, 1977.

16. Koretz RL, Stone O, Gitnick GL. The long-term course of non-A, non-B post-transfusion hepatitis. Gastroentorology 79: 893-898, 1980.

17. Leong AS, Disney AP, Gove DW. Spallation and migration of silicone from blood-pump tubing in patients 
on hemodialysis. New England Journal of Medicine 306: 135-140, 1982.

18. Magnius LO, Espmark JA. New specificities in Australia antigen positive sera distinct from the Le Bouvier determinants. Journal of Immunology 109: 111 7-1021, 1972.

19. Mosley JW, Redeker AG, Feinstone SM, Purcell RH. Multiple hepatitis viruses in multiple attacks of acute viral hepatitis. New England Joumal of Medicine 296: 75-78, 1977.

20. Norkrans G, Frosner G, Hermodsson S, Iwarson S. Multiple hepatitis attacks in drug addicts. Journal of the American Medical Association 243: 1056-1058, 1980.

21. Seaworth BJ, Garrett LE, Stead WW, Hamilton JD. Non- $A$, non-B hepatitis and chronic dialysis - another dilemma. American Journal of Nephrology 4:235-239, 1984.

22. Schimizu YK, Feinstone SM, Purcell RH, Alter HJ, London WT. Non-A, non-B hepatitis: ultrastructural evidence for two agents in experimentally infected chimpanzees. Science 205: 197-200, 1979.

23. Simon N, Mery JP, Trepo C, Vitvitski L, Courouce AM. A non-A, non-B hepatitis epidemic in a $\mathrm{HB}$ antigen-free haemodialysis unit. Demonstration of serological markers of non-A, non-B virus. Proceedings of the European Dialysis and Transplant Association 17: 173-178, 1980.

24. Tabor E, Gerety RJ, Drucker JA, Seeff LB, Hoofnagle JH, Jackson DR, April MDUM, Barker LF, Pineda-
Tamondong G. Transmission of non-A, non-B hepatitis from man to chimpanzee. Lancet 1: 463-466, 1978.

25. Tateda A, Kikuchi K, Numazaki Y, Shirachi R, Ishida N. Non-B hepatitis in Japanese recipients of blood transfusions: clinical and serologic studies after the introduction of laboratory screening of donor blood for hepatitis B surface antigen. Journal of Infectious Diseases 139: 511-518, 1979.

26. Tsiquaye KN, Bird RG, Tovey G, Wyke RJ, Williams R, Zuckerman AJ. Further evidence of cellular changes associated with non-A, non-B hepatitis. Journal of Medical Virology 5: 63-71, 1980.

27. Villarejos VM, Visona KA, Eduarte CA, Provost PJ, Hilleman MR. Evidence for viral hepatitis other than type A or type B among persons in Costa Rica. New England Journal of Medicine 293: 1350-1352, 1975.

30. Yoshizawa H, Itoh $Y$, Iwakiri S, Kitajima K, Tanaka A, Nojiri T, Miyakawa Y, Mayumi M. Demonstration of two different types of non-A, non-B hepatitis by reinjection and cross-challenge studies in chimpanzees. Gastroenterology 81: 107-113, 1981.

28. Ware AJ, Luby JP, Hollinger B, Eigenbrodt EH, Cuthbert JA, Atkins CR, Shorey J, Hull AR, Combes B. Etiology of liver disease in renal-transplant patients. Annals of Internal Medicine 91: 364-371, 1979.

29. Woodman HT, Weiser MM, Venuto R, Walshe J. Outbreak of non-A, non-B hepatitis in a dialysis unit and its characterization. Gastroenterology 79: 1068 (abstr.), 1980. 